\section{Cambodia's killing fields}

\section{Annapolis, Maryland}

TEN years after the Khmer Rouge were driven from Phnom Penh, rice research and production in Cambodia remains a victim of the Pol Pot regime, Glenn Denning of the International Rice Research Institute told a Rockefeller Foundation agricultural research conference last week.

Among the scars left by the Khmer Rouge attacks of the early 1970s are burned rice-research stations like the one shown here. As the Khmer Rouge first advanced towards Phnom Penh, Cambodia's rice farmers abandoned their crops to flee to the cities. By 1975, when Phnom Penh fell, rice-growing area in Cambodia was a fifth of the 2.5 million hectares cultivated five years earlier, Denning said.

In Cham Car Daung, near Phnom Penh, the Khmer Rouge took over the Institute of Agriculture, the country's main agricultural research university. It was converted into an ammunition dump by the Pol Pot regime, then blown up on their departure in 1979. Of the 300 graduates from the institute's heyday between 1969 and 1975 , only 20 have been accounted for. The rest have either 'perished' or left the country, Denning said.

To convert Cambodia to irrigation, $\mathrm{Pol}$ Pot banned traditional deep-water rice and commissioned massive networks of waterways. 'Pol Pot canals' still mark much of the country, but few are functional. Those that are still maintained are used as fish ponds.

During the Khmer Rouge attacks, hungry Cambodians ate their seed rice, losing the ability to plant again. With the

The legacy of the seventies.

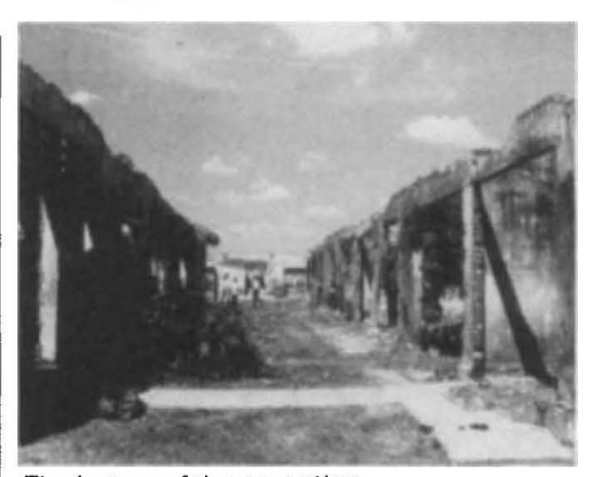

lost fields went hundreds of unique rice species. "It appeared that centuries of selection had been lost," Denning said.

Since 1981, shortly after the first relief workers arrived in Phnom Penh, the International Rice Research Institute (IRRI) based in the Phillipines has reintroduced 562 traditional species to Cambodia, Denning said. Half of the rice now grown in Cambodia comes from species taken from IRRI seed banks. IRRI currently has three scientists stationed in Phnom Penh, including a anthropologist to study traditional farming methods.

After a decade of collective farming in 'crop solidarity groups', Cambodian farmers were last year given the option of $10-20$ year leases on the land they worked and were allowed to market their own crops. Although prices of both rice and fertilizer have subsequently gone up, so has production. Rice-growing land now accounts for 1.8 million hectares. Even so, average yield is only 1.2 tons per hectare — still the lowest in Asia.

G. Christopher Anderson

\title{
Revival of links with Romania
}

\section{Paris}

AfTer 15 years of imposed isolation, the Instituto Cantacuzino in Bucharest has been able to renew contact with the Pasteur Institute in Paris, the institute upon which it was originally modelled. A package of initiatives worked out by the Pasteur Institute aims to bring researchers up to date in the latest techniques of molecular biology and modern virology and to help put the Institute back on its feet.

Set up in the 1920 s, the Instituto Cantacuzino should be playing a central role in efforts to control the spread of hepatitis B and AIDS. But after a decade without access to international science, either through the literature or through travel, researchers have been left far behind.

Training will be offered in Paris to Cantacuzino's best researchers and a 3-week summer school organized in Romania, for about 20-25 researchers.

\section{New man takes over}

London

Michael Merson, a US citizen, is the new head of the World Health Organization's global programme on AIDS. He replaces Jonathan Mann, who resigned in March after disagreements over policy with WHO director-general Hiroshi Nakajima (see Nature 344, 283, 22 March 1990).

Merson has headed WHO's diarrhoeal disease-control programme since 1984, and also took control of its acute respiratory infections programme in 1987. Addressing the 43rd World Health Assembly in Geneva after his appointment, Merson said that WHO's continued cooperation with other non-governmental organizations (NGOs) is essential in the fight against AIDS. Nakajima is believed to have opposed Mann's moves to increase links between the AIDS programme and other NGOs. But Merson's position on the distribution of drugs in developing countries, understood to be another source of disagreement between Mann and Nakajima, is less clear.

Merson's immediate concern is the AIDS programme's budget, planned for $\$ 100$ million in 1991 . But only $\$ 70$ million has been set aside so far. Merson expressed "great concern" if this shortfall cannot be made up, and warned against "complacency" over the global AIDS pandemic.

IN VITRO FERTILIZATION PeterAldhous

\section{Children 'normal'}

\section{London}

CHILDREN conceived by in vitro fertilization (IVF) seem no more likely to suffer congenital abnormalities than the general population, a Medical Research Council working party has concluded. But the infant mortality and still-birth rate in IVF children is twice the UK average because of the high proportion of multiple births.

The survey looked at 1,267 pregnancies in the United Kingdom from 1978 to 1987 , conceived by IVF or gamete intrafallopian transfer (where sperm and eggs are deposited in the fallopian tubes), which resulted in 1,581 live and still-births. Its publication in last week's British Medical Journal is timely, because the Human Fertilization and Embryology Bill, currently passing through parliament, will set up a Statutory Licensing Authority to regulate IVF.

The present Interim Licensing Authority guidelines recommend that three IVF embryos should be placed into the uterus to ensure a reasonable success rate. But this increases the rate of multiple births. In the opinion of Brian Lieberman, from St Mary's Hospital in Manchester, improved preservation of frozen embryos over the next two or three years should mean that multiple births will be common: if spare embryos are preserved, then there will be less initial pressure to obtain successful implantation.

Peter Aldhous 